\title{
The Smell Function Disturbance in Textile Industrial Workers Exposed to Chlorine Gas
}

\author{
Bambang Udji Djoko Rianto*, Wahyu Sigit Purnomo and Siswanto Sastrowijoto \\ Otorhinolaryngology, Head and Neck Surgery Faculty of Medicine, Universitas Gadjah Mada/ Dr. Sardjito Hospital, Yogyakarta, \\ Indonesia \\ *Corresponding author: Bambang Udji Djoko Rianto, Department of Otorhinolaryngology Head and Neck Surgery Faculty of \\ Medicine, Universitas Gadjah Mada / Dr. Sardjito Hospital, Jl. Kesehatan No. 1 Yogyakarta 55281, Indonesia
}

\begin{abstract}
ARTICLE INFO
Received: 幽 May 21, 2019

Published: 慧 May 29, 2019

Citation: Bambang Udji Djoko R, Wahyu Sigit P, Siswanto S. The Smell Function Disturbance in Textile Industrial Workers Exposed to Chlorine Gas. Biomed J Sci \& Tech Res 18(3)-2019. BJSTR. MS.ID.003149.
\end{abstract}

Keywords: Chlorine; Textile Industrial; Worker; Olfactory Disturbance

\section{ABSTRACT}

Objective: Nasal olfactory parts which exposed to toxic agents can cause smelling disturbance. Chlorine is a chemical substance commonly used in the textile industry, to which factory workers are exposed.

Materials and Methods: This research design was an analytic cross-sectional study aimed to compare the smelling function between textile industrial workers exposed to chlorine gas and those not exposed. The subjects were industrial workers exposed to chlorine gas and those not exposed during January until February 2013. The inclusion criteria for the chlorine exposed group were:

a) age 20-55 years,

b) worked in chlorine exposed area, and

c) agree to participate in the study, while the not exposed group worked in the free chlorine area.

Exclusion criteria were:

a. suffered from rhinitis,

b. history of head and nose trauma,

c. history of rhinoplasty,

d. history of smoking, and

e. suffered from nasal tumor.

All samples smelled using camphora, carbon disulfide, vanilla, menthol piperate, ether, capsaicin as standard tool in odor-free rooms. The statistical analyses used $\mathrm{X}^{2}$ tests.

Results: There were 80 workers consisting 40 worker each group. From the exposed group found $10(25 \%)$ with the smell function disturbance and $30(75 \%)$ normal, while the unexposed group $2(5 \%)$ the smell function disturbance and $38(95 \%)$ normal. These results are statistically significant differences ( $\mathrm{p}=0.012$; RP: $6.333 ; 95 \% \mathrm{CI}$ : 1.289-31.115).

Conclusion: There was a significant difference in smelling function disturbance between workers exposed to chlorine and those not exposed to chlorine.

\section{Introduction}

Many patients suffer from olfactory disorders or smelling function disturbance. Based on research in America there are 2.7 million adults who have a disturbance in the sense of smell.
Impaired smelling function experienced by a person increases with age [1]. Smelling disturbance is generally difficult to diagnose and treat, usually due to a lack of knowledge in the individual. 
Secondary invasion disorders may occur as a result of illness or as a primary complaint. Missing or diminished disappearance occurs in approximately $2 \%$ of the age group below 60 years and more than $50 \%$ in the over 60 years old group [2]. Some anatomical locations identified as the cause of smell function disturbances include olfactory abnormalities in mucous membranes in the nasal cavity, olfactory nerve disorders and central nerves. Smell function disturbance can be caused by pathological processes along the path of olfactory function. This disorder is considered similar to hearing loss which is a conductive or sensorineural defect. In the conductive defect (transport) there is a disturbance in the transmission of odor stimulus to the olfactory neuroepithelial.

While many reasons such as environmental exposure to contaminants and smoking have been found to contribute to smelling function disorders, in the sensorineural defect the process involves a more central nervous structure [3]. Another study investigated the detrimental effects of gasoline vapor exposure in causing respiratory disorders in the operator workers at the pumping station. The results of the study found that from 38 workers who carried out the scrubbing test by using the concentration of the threshold value and the recognition value of 6 ingredients there was a significant decrease in the olfactory function in the workers with exposure to gasoline vapor compared to the control group [4]. Overall, the main causes of the olfactory disorders are changes in the nasal or sinus cavities, upper respiratory tract infections due to virus and/or head trauma, endocrine disorders, tumors, psychiatric disorders, aging, medications, chemicals, environmental pollution and industrial and iatrogenic factors. These toxic substances associated with disturbances and loss of smelling function can be pollutants from industries such as chlorine. The ordinary textile industry uses large amounts of chlorine and involves a lot of manpower [3]. Based on the above health concerns, this study aimed to compare the smelling function between workers exposed to chlorine gas and those not exposed to chlorine gas in the textile industry.

\section{Patients and Methods}

This research was an analytic study using a cross-sectional design conducted by comparing 2 groups of samples: industrial workers exposed to chlorine and industrial workers not exposed to chlorine gas. The study was conducted from January to February 2013 at textile industry, Tangerang West Java, Indonesia. The research procedures included:

i) anamnesis from the study subjects, including subject data, current disease history, prior illness, and family disease history, and

ii) anterior and posterior rhinoscopy for vestibules, nasal mucosa and septum, lateral and inferior wall of the nose examination.

The scrubbing test used volatile substances: camphora solution, capsaicin, vanilla, oleum menthol piperate, and ether with predetermined concentrations to test subjects' ability to detect and recognize odors. The study was conducted after receiving approval from the Medical and Health Research Ethics Committee (MHREC) Faculty of Medicine, Universitas Gadjah Mada Ref: KE/FK/171/EC. The inclusion criteria for the chlorine exposed group were:

(1) Age 20-55 years,

(2) worked in chlorine exposed area, and

(3) agreed to participate in the study,

while for the not chlorine exposed group:

(a) age 20-55 years,

(b) workers who were in the free chlorine area in the surrounding air.

Exclusion criterion were:

(1) suffered from rhinitis

(2) history of head and nose trauma,

(3) history of rhinoplasty,

(4) history of smoking, and

(5) suffered from nasal tumors.

The smell test was conducted in odor-free rooms, using the standardized 6 types of smell substances.

The volatile agent used was placed in a closed tube. Each tube was filled with the respective standard concentrations for detection and identification,

(i) camphora tube,

(ii) carbon disulfide tube,

(iii) vanilla tube,

(iv) oleum menthol piperate tube,

(v) ether tube, and

(vi) capsaicin tube.

The subjects of the study were asked to remove the volatile substances from tubes I to VI and place them $1 \mathrm{~cm}$ away from the right or left anterior nares at intervals up to one minute at ordinary inspiration, repeating 2-3 times (respiration 20 times per minute). After inhaling the subjects were asked to mention the type of smell inhaled. When this smelling step was complete, subjects were asked to proceed with the odor identification checklist which involved completing a standardized questionnaire. Sample size calculation based on different proportions, $\alpha$ : 5\%; $\beta: 20 \%$ and $95 \%$ confidence interval, showed recommended total samples were 40 workers for each group. Statistical analysis used Chi square test, independent sample t-test and Prevalence Ratio (RP). The significance level in the statistics was $\mathrm{p}<0.05$, with $95 \%$ confidence level. 


\section{Results}

The results of demographic data of research subjects can be seen in Table 1 below.

The main aim in this research was to determine the effect of exposure to chlorine on the smell function disturbance in industrial workers at the textile factory. The main statistical test used was Chi- square test. The main outcome research results can be seen in Table 2 below.

Table 1: Demographic data.

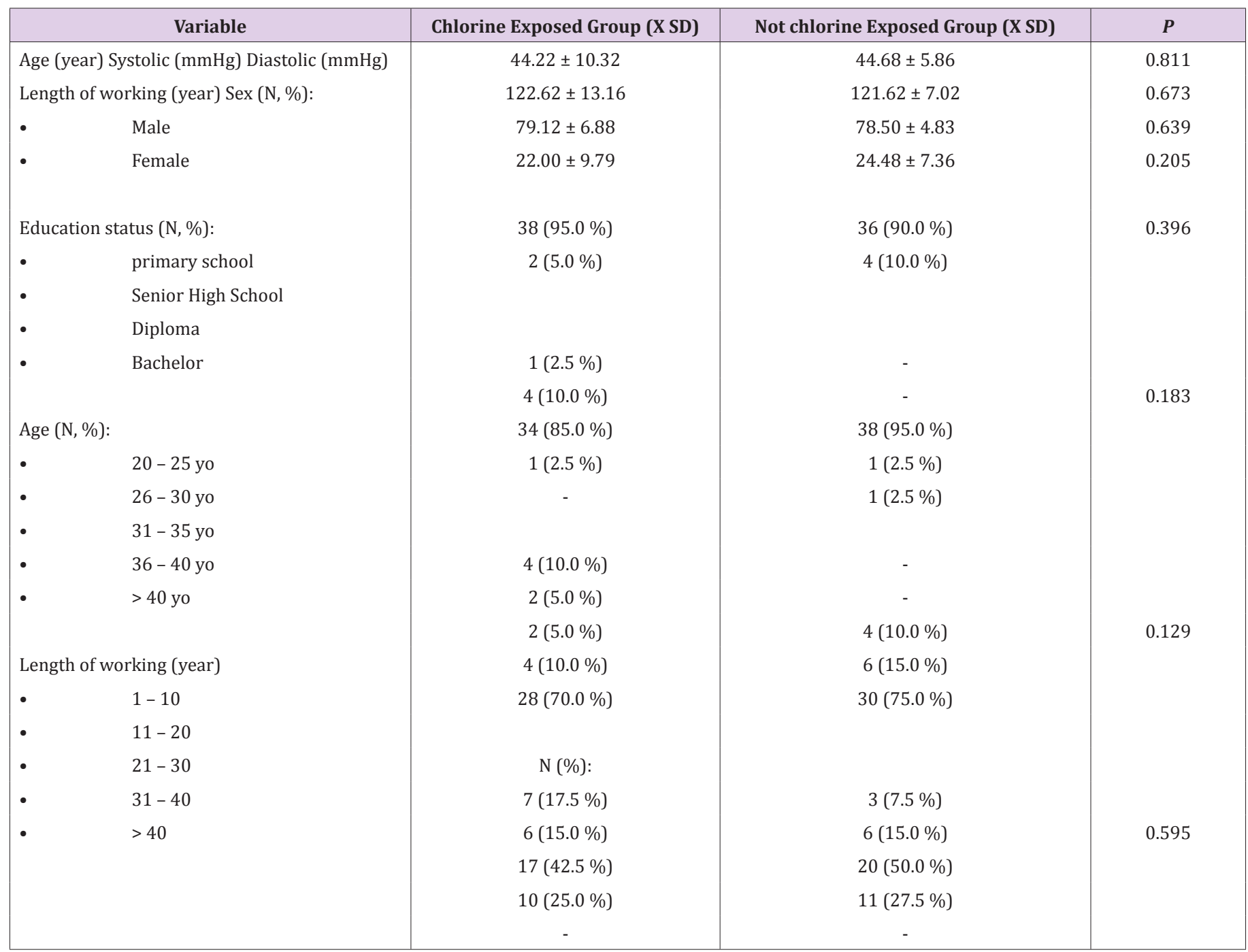

Table 2: The distribution smell function of study subject.

\begin{tabular}{|c|c|c|c|c|c|}
\hline & \multicolumn{2}{|c|}{ Smell Function } & \multirow{2}{*}{ RP } & \multirow{2}{*}{$95 \% \mathrm{CI}$} & \multirow{2}{*}{$p$} \\
\hline & Disturbance N (\%) & Normal N (\%) & & & \\
\hline \multicolumn{6}{|l|}{ Worker } \\
\hline Chlorine exposed & $10(25 \%)$ & $30(75 \%)$ & 6.333 & $1.289-31.115$ & $0.012^{*}$ \\
\hline $\begin{array}{l}\text { Not exposed to } \\
\text { chlorine }\end{array}$ & $2(5 \%)$ & $38(95 \%)$ & & & \\
\hline \multicolumn{6}{|l|}{ Sex } \\
\hline Male & $10(26.3 \%)$ & $28(73.7 \%)$ & 1.071 & & \\
\hline Female & - & $2(100 \%)$ & & 0.974-1.179 & 0.402 \\
\hline \multicolumn{6}{|l|}{ Length of working: } \\
\hline$\geq 22$ yo & $9(34.6 \%)$ & $16(64.0 \%)$ & & & \\
\hline
\end{tabular}




\begin{tabular}{|c|c|c|c|c|c|}
\hline$<22$ yo & $1(7.1 \%)$ & $14(93.3 \%)$ & 7.875 & $0.884-70.151$ & $0.038^{*}$ \\
\hline Age: & & & & & \\
\hline$\geq 44$ years old & $9(34.6 \%)$ & $17(65.4 \%)$ & & & \\
\hline$<44$ years old & $1(7.1 \%)$ & $13(92.9 \%)$ & 6.882 & $1.771-61.406$ & $0.049^{*}$ \\
\hline
\end{tabular}

*Statistically significant; $\mathrm{p}<0.05$.

\section{Discussion}

Demographic data was the basic data of the research subjects in each study group consisting of age, sex, education level, systolic blood pressure, diastolic blood pressure, and duration of work. Independent t-test statistics were used to determine the comparison of mean age, systolic blood pressure, diastolic blood pressure and duration of work, while Chi-square tests were used to compare the distribution of research subjects by sex, education level, age group of subjects, and length at work of research subjects (Table 1). Table 2 shows that the smell function disturbance in the chlorine exposure group were 10 (25\%) and the normal smell ability were 30 (75\%), while the smell function disturbance in the not chlorine exposed group were $2(5 \%)$ and the normal smell function were 38 (95\%) samples. These results show statistically significant differences in the nasal interference between the chlorine exposure group and the chlorine-free group ( $p=0.012)$. This study obtained RP value: 6.333 means that the study subjects in the environment exposed to chlorine are 6.333 times more likely to experience a smelling function disturbance compared to the not chlorine exposed group. RP value of 6.333 can be interpreted also that the probability of research subjects in the environment exposed to chlorine that experienced disturbance was $86.36 \%$.

Previous studies in animals exposed to chlorine concentrations of 1 ppm caused olfactory disorders. In another study of the effect of $1 \mathrm{ppm}$ chlorine exposure on 139 workers exposed to chlorine, 55 (36.5\%) workers experienced shortness of breath requiring oxygen therapy [5]. Other study demonstrated that exposure to chlorine which exceeds the threshold can cause disturbance of smell. The results of this study reported that exposure to chlorine that exceeds the threshold can cause irritation of the mucosa and upper respiratory tract. Even with levels of 20-2000 ppm chlorine gas exposure can cause death due to the occurrence of epithelial damage in the respiratory tract. At a concentration of $17 \mathrm{ppm}$ with 10 minutes of exposure time chlorine gas can cause damage to the eye mucosal epithelium and upper respiratory tract, one of which is the nasal mucosa [2]. Chlorine is a yellow-green non-combustible gas with a pungent irritating odor. It is widely used in textile industries and is one of the most commonly produced chemical substances worldwide. Chlorine gas is partially soluble in water, and upon inhalation is often deposited on hygroscopic surfaces such as the eyes, nose [6,7]. Chlorine reacts with water in the mucous membranes and airways to form hydrochloric and hypochlorous acids leading to acute inflammation of the conjunctiva, nasal mucosa, pharynx, larynx, trachea, and bronchi.
The oxidation of functional groups in cell components and the generation of free oxygen radicals are also thought to cause cellular injury $[8,9]$. In this study, there was no statistically significant difference in smell function between males and females (Table 2). To demonstrate that age more than 44 years has increased risk of occurrence of olfactory disturbance this can be seen by using the average age of research subject is 44 years, so the division of age group is more or equal to 44 years and less than 44 years, and the research result can be seen in Table 2 . There were significant differences in olfactory interference between the age group $\geq 44$ years compared to the age group $<44$ years in industrial workers exposed to chlorine $(\mathrm{p}<0.049)$. This study obtained RP value of 6.882 which means that people in the environment exposed to chlorine with age $\geq 44$ years are 6.882 times more likely to experience a disturbance of smell compared to subjects in the same environment exposed to chlorine with age $<44$ years. The value of RP of 6.882 can be interpreted also that the probability of people in the environment exposed to chlorine with age $\geq 44$ years experienced a disturbance of smell was $87.31 \%$. In addition to chlorine exposure, the age-related annihilation disorder is a degenerative process that involves the aging process which results in decreased surface area of olfactory epithelium and decreased adrenergic reserves in lamina propria while calcium bound protein elements also decrease in number resulting in a buffering disorder.

This degenerative disorder reinforces opinions in other studies which state the olfactory bulb undergoes degenerative changes so that the number of cell bodies and neurons are reduced in number during the ageing process $[2,8]$. Table 2 indicates that there is a significant difference in the disturbance of smell between the long working $\geq 22$ years old group compared to $<22$ years old group on industrial workers exposed to chlorine ( $p \leq 0.05$; $p=0.038$ ). From the results of this study we obtained RP value of 7.875 which means that the study subjects exposed to chlorine with a working time of $\geq$ 22 years are 7.875 times more likely to experience the disturbance of smell compared to people in the same environment exposed to chlorine with a working length $<22$ years. The value of RP of 7.875 can be interpreted also that the probability of people in the environment exposed to chlorine with a working time of $\geq 22$ years to experience the disturbance of smell was $88.77 \%$. In the textile industry, chlorine is the main substance in the bleaching process. In the textile industry, chlorine is the main substance in the bleaching process, but can cause inflammation of the nasal and respiratory tract mucosal [10]. Previous studies reported the occurrence of lesions in the olfactory nerve in the form of redistribution of 
calcium carbonate which subsequently caused olfactory nerve damage $[11,12]$.

This layer is comprised of the alkaline phospholipid component which reacts rapidly to calcium carbonate resulting in protein denaturation which further causes damage to the olfactory epithelium [13]. Exposure to chlorine $2 \mathrm{ppm}$ in the air can cause irritation to the nasal mucosa. Exposure to concentrated chlorine in the respiratory tract includes irritation of the upper respiratory tract which is characterized by hyperemic and edema of the nasal mucosa $[14,15]$. Exposure to chlorine in the concentration threshold between 0.1-0.3 ppm is still considered safe. 1-3 ppm concentration exposure causes mild mucous membrane irritation which can be tolerated for one hour, while 5-15 ppm causes moderate mucous membrane irritation. The limit of exposure at work for 15 minutes is recommended not to exceed 1 ppm (2.9 mg / $\mathrm{m} 3)$. The long-term exposure limit for 6 hours is recommended not to exceed 0.5 ppm (1.5 mg / m3) [16]. Chlorine can break down and produce hypocaloric acid and hydrochloric which produce oxygen free radicals. In high-dose exposure, acids and free radicals damage the cell walls that interact with sulfhydryl groups in amino acids and enzyme systems in the mucosal epithelium. This causes edema, erosion, desquamation, and necrosis of epithelial cells [17-19]. Chlorine exposure can also interact quickly with special sensory structures of the nose, causing inflammation of the olfactory nerve. This often happens to workers exposed to chlorine [20].

\section{Conclusion}

Workers exposed to chlorine gas had a probability of smell disturbance 6.333 times greater compared to workers not exposed to chlorine in the textile industry.

\section{Acknowledgment}

Thanks goes to the patients and parents, and also all research assistants (ENT Residents and Nurses) who participated in this research, and to Director of DR. Sardjito General Hospital, Director \& employer PT Argo Pantes Garment Tangerang and Medical \& Health Research Ethics Committee Faculty of Medicine, Universitas Gadjah Mada that gave license, permission and approval for this research.

\section{References}

1. Kobayashi M, Reiter ER, DiNardo LJ, Costanzo RM (2007) A new clinical olfactory function test cross- cultural influence. Arch Otolaryngol Head Neck Surg 133(4): 331-336.

\section{ISSN: 2574-1241}

DOI: 10.26717/BJSTR.2019.18.003149

Bambang Udji Djoko Rianto. Biomed J Sci \& Tech Res

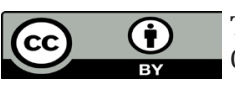

This work is licensed under Creative Commons Attribution 4.0 License

Submission Link: https://biomedres.us/submit-manuscript.php
2. Murphy C, Schubert CR, Cruickshanks KJ, Klein BE, Klein R, et al. (2002) Prevalence of olfactory impairment in older adults. JAMA 288(18): 2307-2312.

3. Malaty J, Malaty IA (2013) Smell and taste disorders in primary care. Am Fam Physician 88(12): 852-859.

4. Rianto BUD, Yudhanto D, Herdini C (2018) The Correlation Between Length of Work and Nasal Mucociliary Transport Time of Gas/Fuel Station Workers. Kobe J Med Sci 64 (1): 6-10.

5. Berghoff, RS (1999) The more common gases-their effect on the respiratory tract. Observation on two thousand cases. Arch Intern Med 24(6): 678-684

6. Chester EH, Kaimal, J, Payne CB, Kohn PM, Kohn (1997) Pulmonary injury following exposure to chlorine gas. Chest 72(2): 247-250.

7. Rupp CL (2004) Olfactory functioning in patient with alcohol dependence: impairment in odor judgement. Alcohol Alcohol 39(6): 514-519.

8. Van Sickle D, Wenck MA, Belflower A, Drociuk D, Ferdinands J, et al. (2009) Acute health effects after exposure to chlorine gas released after a train derailment. Am J Emerg Med 27(1): 1-7.

9. Segal E, Lang E (2010) Toxicity, chlorine gas. eMedicine Emergency Medicine p. 1-16

10. Kanikowska, A, Napiórkowska Baran A FK, Graczyk, M, Kucharski MA (2018) Influence of chlorinated water on the development of allergic diseases- An overview. Ann Agric Environ Med 25(4): 651- 655.

11. Feron VJ, Arts JHE, Kuper CT (2001) Health risk associated with inhaled nasal toxicants. Crit Rev Toxicol 31(3): 313-347.

12. Ship JA, Pearson JD, Cruise LJ, Brant LJ, Meter EJ (1996) Longitudinal changes in smell identification. J Gerontol Med Sci 51(2): 86-91.

13. Segal MD (2012) Chlorine gas toxicity. Am J Emerg Med 29(1): 1-5.

14. Jones R, Wills B, Kang C (2010) Chlorine gas: an evolving hazardous material threat and unconventional weapon. West J Emerg Med 11(2): 151-156.

15. Toprak S, Kalkan EA (2016) A Case Report: What is the Real Cause of Death from Acute Chlorine Exposure in an Asthmatic Patient? Int J Respir Pulm Med 3(2): 1-2.

16. White CW, Martin JG (2010) Chlorine Gas Inhalation Human Clinical Evidence of Toxicity and Experience in Animal Models. Proceedings of the American Thoracic Society 7(4): 257-263.

17. Jiang Hua L, Zhi Hui W, Xiao Juan Z, Zhao Hui D, Can Xin C, et al. (2015) Health Effects from Swimming Training in Chlorinated Pools and the Corresponding Metabolic Stress Pathways. PLoS One PLOS ONE 5: 1-14.

18. de Genaro IS, de Almeida FM, Hizume Kunzler DC, Moriya HT, Silva RA, et al. (2018) Low dose of chlorine exposure exacerbates nasal and pulmonary allergic inflammation in mice. Scientific Reports p. 1-13.

19. Meggs WJ (2017) The Role of Neurogenic Inflammation in Chemical Sensitivity. Ecopsychology 9(2): 83-89.

20. Shusterman D (2011) The Effects of Air Pollutants and Irritants on the Upper Airway. Proc Am Thorac Soc 8(1): 101-105.

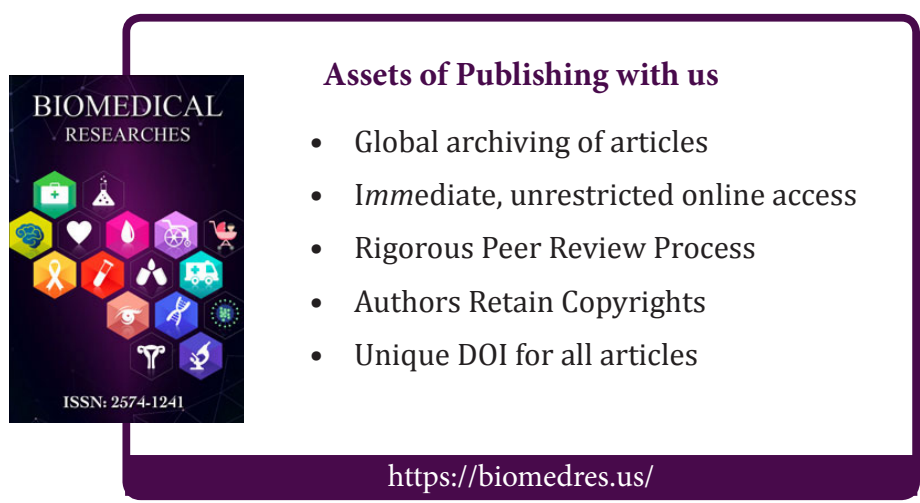

